\title{
Health economics of heart failure
}

\author{
M Malek
}

The pharmacoeconomics of heart failure are relatively easy to analyse for two reasons. Firstly, sufficient data on resource utilisation, such as hospital bed days or drug consumption, are available; net patient costs are easily identifiable and measurable in monetary terms. Secondly, the outcome, in terms of mortality, morbidity, and lost quality of life, is also straightforward to measure owing to a number of large clinical trials which have been performed in patients with heart failure. Despite this, however, very few pharmacoeconomic evaluations of $\beta$ blockers in heart failure have been carried out.

The treatment costs of heart failure are relatively high. It has been estimated that in western industrialised countries, between $1-2 \%$ of total annual health care expenditure is related to the care of patients with heart failure. ${ }^{1}$ In the US patients with heart failure have been said to account for $1.5 \%$ of health care expenditure, while in France the figure is quoted as being as high as $1.9 \% .^{23}$ In the UK and the Netherlands, the equivalent percentages are $1.2 \%$ and about $1 \%$, respectively. ${ }^{4}$ These figures, however, have been calculated from data that are up to 10 years old (table 1 ).

In heart failure, costs are driven mainly by hospital admission charges and are relatively constant between health care systems as a proportion, representing $67-75 \%$ of the total cost of treating a patient. ${ }^{4}$ There is also a positive correlation between the cost of heart failure treatment for a particular individual and the severity of their disease. The relation is non-linear and rises almost exponentially as the New York Heart Association (NYHA) class of heart failure goes up. Looking at the various figures from publications relating to different countries it is apparent that costs almost double with the jump between NYHA class I/II and III. There is also a major cost differential between treating patients with NYHA class III and class IV heart failure (table 2).

\section{CIBIS I pharmacoeconomics}

Some of the pharmacoeconomic studies which have been conducted in heart failure are derived from the first cardiac insufficiency bisoprolol study (CIBIS I), which involved a

Table 1 Heart failure and economics: cost of heart failure in industrialised countries related to total health care costs

University of St Andrews, School of Social Sciences, St Katherine's West, The Scores, St Andrews KY16 9AL, UK M Malek

Correspondence to: Professor Malek email:mml@st-and.ac.uk FF, French francs; NLG, Netherlands guilders; $£$, pounds sterling.

\begin{tabular}{lll} 
Country (year) & Cost & $\begin{array}{l}\text { Percentage of total } \\
\text { health care } \\
\text { expenditure (\%) }\end{array}$ \\
\hline US (1989) & US\$9 billion & 1.5 \\
France (1990) & FF11.4 billion & 1.9 \\
UK (1990-91) & E360 million & 1.2 \\
Netherlands & NLG444 million & 1.0
\end{tabular}

US $\$ 1=£ 0.63$, FF5.00, NLG1.60 (October 1995 exchange total of 641 patients. $^{6}$ Although there was a $20 \%$ reduction in mortality in the treatment arm compared to placebo, this was not significant. Their was a significant reduction in the number of hospital admissions in the bisoprolol treatment arm, however, and there was also a significant improvement in functional status of the treated group.

The results of CIBIS I were used in three pharmacoeconomic studies, all of which have been published recently. The first, a French study by Levi and colleagues, looked at a number of hospital admissions and medication costs in each treatment group. ${ }^{7}$ They based estimates of the distribution of hospital admissions on critical events and have used direct costs per diagnosis related group about which they have additional information in France. The results of the study show an approximate FF5000 (US $\$ 1000$ ) saving in treatment costs among patients with a history of myocardial infarction (fig 1). With regard to the whole study population, there is the same order of cost saving of FF4500 (\$900) per patient between the placebo group and the treatment group. So clearly it is cost effective to use $\beta$ blockers in this patient group.

Table 2 Annual cost of heart failure related to New York Heart Association (NYHA) class

\begin{tabular}{lrccr}
\hline \multirow{5}{*}{$\begin{array}{l}\text { NYHA } \\
\text { class }\end{array}$} & $\begin{array}{l}\text { Costs } \\
\text { France } \\
\text { (FF) }\end{array}$ & $\begin{array}{l}\text { The Netherlands } \\
\text { (NLG) }\end{array}$ & $\begin{array}{l}\text { Germany } \\
\text { (DM) }\end{array}$ & $\begin{array}{l}\text { Belgium } \\
\text { ('OOO BeF) }\end{array}$ \\
\hline I-II & 5760 & 700 & 2580 & 32000 \\
III & 22126 & 1200 & 4428 & 78000 \\
IV & 44300 & 23000 & - & 1000000 \\
\hline
\end{tabular}

US\$1 = FF5.00, NLG1.60, DM1.42, BeF38 (October 1995 exchange rates).

FF, French francs; NLG, Netherlands guilders; DM, German deutschmarks; BeF, Belgian francs.

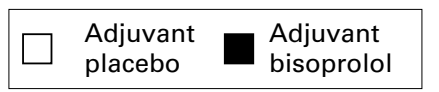

Patients without history of myocardial infarction

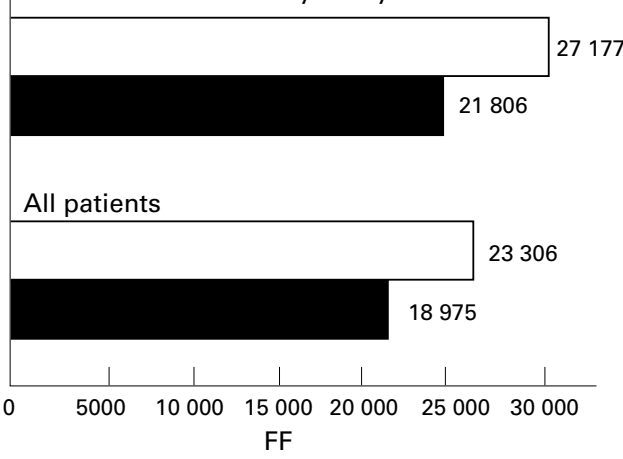

Figure 1 Retrospective health economic analysis of CIBIS $I$ (France): mean cost per patient (US\$1 = FF5). 


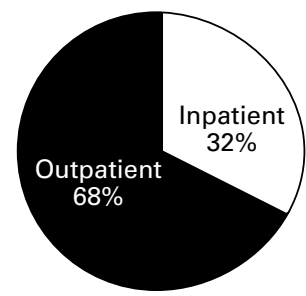

Figure 2 MEMO study: ratio of inpatient versus outpatient care after hospital admission. ${ }^{9}$
The second study analysed the same data using German medication costs, differences in hospital admissions, average length of stay, and per diem costs in different hospital categories in Germany. ${ }^{8}$ Depending upon the hospital type, the savings per patient per year from the statutory health insurance's perspective lie between DM68 (\$48) and DM862 (\$607). So even in the worst case scenario, treatment would be at least cost neutral.

In order to analyse the CIBIS I data in UK pharmacoeconomic terms, we used resource utilisation data from the medicines monitoring unit (MEMO) in Dundee. ${ }^{9}$ Costs were estimated based on medication, difference in hospital admissions, and whether treatment occurred in an inpatient or an outpatient setting.

In the CIBIS I study, only information on hospital admissions was collected in detail. Our analysis used data collected at MEMO showing the ratio of inpatient to outpatient care in order to estimate the missing data for the number of outpatient visits. The average cost that would be incurred per outpatient visit is approximately $£ 250$ ( $\$ 400$ ), whereas the average inpatient stay cost is about $£ 2000$ (\$3200) (fig 2).

Using these data, the average cost per patient over the 1.9 year study period was calculated and showed only a minor difference between the active and placebo groups (fig 3). The reduction in hospital costs was offset by additional costs of bisoprolol so the treatment emerged as cost neutral. The highest dose of the drug, $10 \mathrm{mg}$ per day, at full price was used for calculation purposes.

The limitations of performing these studies are the lack of reliable cost data for each individual patient. Improvements in NYHA class, which were quite prominent in the CIBIS I study, were not taken into account. It should also be remembered that this pharmacoeconomic study was retrospective.

The question that must be asked is why the results in France, Germany, and Britain are so different. The principal reason for costs being neutral in the UK versus cost savings made in France and Germany is because of differences in funding structure and health care management. There are also many practice variations in how frequently and how intensively services are used. Finally, the cost of many other input factors is substantially different between the different countries.

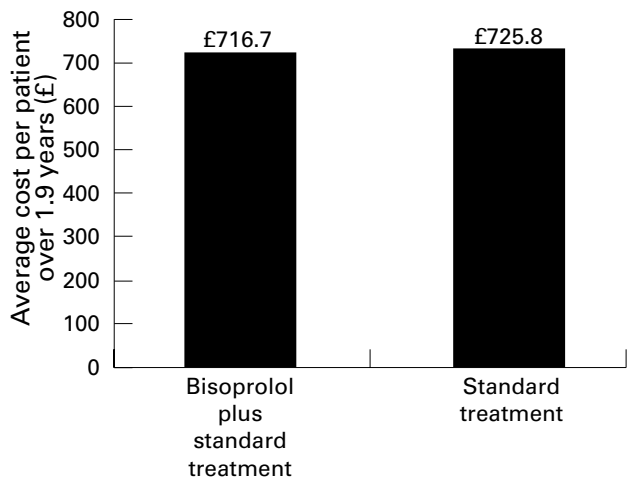

Figure 3 Retrospective health economic analysis of CIBIS (UK). US $\$ 1=£ 0.63$
CIBIS II study

Although a full, formal, economic analysis of CIBIS II data is currently underway, I have made a few approximate calculations based upon the information already in the public domain. ${ }^{10}$

There are a number of assumptions that have to be made. Firstly, the data that have been published for hospitalisation relate to the number of patients hospitalised over an average of 1.3 years and not the actual number of hospitalisations; it must be assumed therefore that each patient admitted was hospitalised just once. Secondly, the cost of drug treatment assumes a worst case scenario of all patients reaching a $10 \mathrm{mg}$ dosage (National Health Service (NHS) price $£ 9.61$ (\$15) for 28 days).

There were 73 fewer patients (513 v 440) hospitalised for any reason in the bisoprolol group and 73 fewer (232 v 159) for worsening heart failure (hazard ratio $0.64,95 \%$ CI 0.53 to $0.79)$. It will be assumed, therefore, that the reduction in hospital admissions was caused by reduced heart failure admissions alone and cost analyses in this respect will be based on admissions for heart failure alone. In the study the reduction in patients admitted to hospital for worsening heart failure was $31.5 \%$.

The average patient on bisoprolol in the CIBIS II study might be expected to live five years. It is assumed that annual costs or savings in the period of the study would be true for all the remaining years of the patient's life. Life expectancy in the carvedilol heart failure trials programme was 7.62 years under the best scenario, probably reflecting a less severely ill population than in CIBIS II.

There is one important difference between the results in CIBIS I and CIBIS II, probably owing to the greater power of CIBIS II-a significant reduction in mortality. The estimated annual mortality rate was $8.8 \%$ in the bisoprolol group and $13.2 \%$ in the placebo group. Thus, on average a patient receiving bisoprolol may be expected to gain about an extra 1.5 years of life.

The total annual cost to the NHS from heart failure, adjusted for inflation, is around $£ 550$ million (\$873 million). Hospitalisation accounts for $67-75 \%$ of the total cost-that is, $£ 350$ million ( $\$ 555$ million). A reduction of $32 \%$ in these costs would equate to a saving of $£ 112$ million ( $\$ 177$ million). If, on the other hand, it is assumed that there are one million treated heart failure patients in the UK, and that the average cost of an inpatient stay for heart failure is $£ 2000$ ( $\$ 3200$ ), the placebo group admission data suggest total inpatient treatment costs of $£ 270$ million ( $\$ 430$ million). The equivalent calculation for the bisoprolol treated group would suggest a total annual cost of $£ 184$ million ( $\$ 290$ million), a saving of $£ 86$ million ( $\$ 135$ million).

However, increased survival implies increased cost in terms of hospital admission during the extra life years; if average life expectancy is increased by 1.5 (undiscounted), or around $30 \%$, this effectively offsets the saving from a $32 \%$ reduction in hospital admissions. The final cost of increased life expectancy is higher than 
this because of non-CHF related expenditure that is not accounted for in this brief analysis. The data for carvedilol ${ }^{11}$ are very similar for the "extended benefits" scenario, taking into account the higher average cost of a congestive heart failure $(\mathrm{CHF})$ inpatient stay in the US of about $\$ 7000$ and higher background drug costs. Essentially in both the carvedilol study and the above estimate for bisoprolol, if the additional cost of non-CHF care is ignored, the cost of achieving an increase in life expectancy is the expenditure on the $\beta$ blocker itself.

The increase in life expectancy from the carvedilol study was 0.95 years and the monthly drug cost quoted for carvedilol was $\$ 90$, although in the UK at the target dose of $25 \mathrm{mg}$ it is $£ 26.30$ (\$42); that for bisoprolol in the UK is $£ 9.61$ (\$15). This suggests UK costs per extra life year (undiscounted) of $£ 2700$ $(\$ 4300)$ and $£ 680$ (\$110), respectively, assuming a similar increase in life expectancy $(0.95$ years). As mentioned above, the cost of non-CHF care for the extra year of life expectancy should be added to these figures, but it is assumed that this will not differ between treatments.

These are all approximate calculations and the final cost-benefit data have yet to be published. Nevertheless, they give a very clear indication of the probable cost of a reduction in annual mortality of one third for those patients prescribed bisoprolol on an intention to treat basis. In this instance, what makes clinical sense also makes economic sense.

1 Harlan WR. Economic considerations that influence health policy and research. Hypertension 1989;13(supp 1):1-163.

2 Harlan WR, Thomas JW, Hurt HA, et al. Health care utilization and costs of adult cardiovascular disease, national medical care utilization and expenditure survey. Public Health Service, Series C, No 7, DHHS Publication No 89-20407. Washington DC: US Government Printing Office, 1989.

3 Kupersmith J, Holmes-Royner M, Hogan A, et al. Kupersmith J, Holmes-Royner M, Hogan A, et al.
Cost-effectiveness analysis in heart disease 1: general prinCost-effectiveness analysis in heart disease $1:$
ciples. Prog Cardiovasc Dis 1995;37:243-71.

4 McMurray J. An evaluation of the cost of heart failure to the NHS in the UK. Brf $\mathcal{F}$ ed Econ 1993;6:99-110.

5 McMurray J, Davie A. The pharmacoeconomics of ACE inhibitors in chronic heart failure. PharmacoEconomics 1996;9:188-97.

6 CIBIS Investigators and Committees. A randomised trial of beta blockade in heart failure. Circulation 1994;90:176573.

7 Levy P, Lechat P, Leizorovicz A, et al. A cost-minimization of heart failure therapy with bisoprolol in the french setting: an analysis from the CIBIS trial data. Cardiovasc Drug Ther 1998;12:301-5.

8 Schaedlich PK, Paschen B, Brecht JG. Economic evaluation of the CIBIS study for the Federal Republic of Germany. PharmacoEconomics 1998;13:147-55.

9 Clarkson P, Perry J, Cunningham-Davis J, et al. Costs associated with symptomatic heart failure. PharmacoEconomics. [In press.]

10 CIBIS II Investigators and Committees. The cardiac insufficiency biroprolol study II (CIBIS II): a randomised trial. Lancet 1999;353:9-13.

11 Delea TE, Vera-Llonch M, Richner RE, et al. Cost effectiveness of carvedilol for heart failure. Am $\mathcal{f}$ Cardiol 1999;83:890-6. 